\title{
FABRICAÇÃO DE BLOCOS ESTRUTURAIS DE CONCRETO COM RESÍDUOS DE BORRACHA DE PNEUS
}

\section{MANUFACTURE OF CONCRETE STRUCTURAL BLOCKS WITH RESIDUES OF TIRE RUBBER}

\author{
Fioriti, C.F ${ }^{1}$; Akasaki, J.R. ${ }^{2}$ \\ ${ }^{1}$ Mestre em Engenharia de Estruturas, Faculdade de Engenharia de Ilha \\ Solteira, Universidade Estadual Paulista - UNESP, Ilha Solteira - S.P, \\ cffioriti@hotmail.com \\ ${ }^{2}$ Professor Doutor, Depto de Engenharia Civil, Faculdade de Engenharia de \\ Ilha Solteira, Universidade Estadual Paulista - UNESP - Campus de Ilha \\ Solteira \\ Alameda Bahia, 550 - Centro - 15385-000 - Ilha Solteira - SP - Fone: \\ (18) 3743-1213 akasaki@dec.feis.unesp.br
}

\section{RESUMO}

O presente trabalho avalia a técnica de fabricação de blocos de concreto com função estrutural utilizáveis em alvenaria. Foram adicionados nos compósitos de concreto, resíduos de borracha provenientes do processo mecânico de recauchutagem de pneus. Prepararam-se cinco diferentes dosagens de concreto contendo resíduos de borracha e uma sem resíduos para servir como referência. Aos 28 dias de idade os blocos produzidos foram submetidos aos ensaios de resistência mecânica à compressão simples e capacidade de absorção de água.

$\mathrm{O}$ intuito deste trabalho foi à obtenção de um possível material alternativo para a indústria da construção civil, contribuindo dessa maneira para a proteção ambiental e a conservação das fontes naturais de materiais convencionalmente utilizados, pois os resíduos da recauchutagem de pneus podem ser definidos como resíduos sólidos particularmente intratáveis, já que sua decomposição pode se estender até 240 anos. E embora existam oportunidades para reciclagem dos resíduos de pneus, o mercado brasileiro está longe de consegui-lo visto à enorme quantidade deste material que é acumulada.

Palavras Chave: blocos de concreto, resíduos de borracha, material alternativo. 


\begin{abstract}
The present work evaluates the manufacture technique of concrete blocks with structural function used in masonry. Rubber residues from the mechanical process of tire retreading was added in the concrete composite. Five different concrete mixes had been prepared with the residues and one concrete mixes without the residues to serve as comparison. In a 28 days time frame the blocks had its compression strength measured as well as the water absorption capacity.

The aim of this work was to obtain a viable alternative material for the civil construction industry, contributing for the environment protection and the conservation of natural sources of conventionally used materials. Therefore the residues proceeding from retreading of tires can be defined particularly as difficult recycling solid residues, since its decomposition can happen in up to 240 years. Even if exists chances for recycling the tires' residues, the Brazilian market is far away from getting it because of the enormous amount of accumulated material.
\end{abstract}

Key words: blocks of concrete, rubber residues, alternative material.

\title{
1. INTRODUÇÃO
}

Com a chegada do século XXI, os fabricantes de blocos estão cada vez mais utilizando processos totalmente mecanizados e automatizados. De atividade tipicamente manual de construção civil, chegamos a um processo industrial que vem se desenvolvendo enormemente pelo mundo. Não obstante ser possível fabricar bons produtos artesanalmente, a necessidade atual de quantidade, qualidade e padronização vem empurrando os fabricantes para um grau de automação cada vez maior.

Segundo Holanda (2000), os blocos estruturais de concreto são materiais que atualmente estão sendo bastante utilizados na construção civil. Apesar de sua utilização datar de tempos remotos, a alvenaria como é vista hoje, é tratada como um método construtivo recente. Destacou também que o bloco de concreto pode ser especificamente definido como a unidade da alvenaria constituída pela mistura homogênea do concreto, adequadamente proporcionada pelas quantidades de cimento, agregado miúdo e água, conformada através de vibro-prensas automáticas, detentoras de um alto poder de vibração e prensagem.

Contudo, com o avanço da tecnologia, a utilização de resíduos industriais está se tornando cada vez mais importante na construção civil. No início dos anos 60 uma grande variedade de resíduos e de materiais foi 
introduzida no mercado, o que vêm acontecendo até nossos dias, à medida que são realizadas novas aplicações.

Um estudo feito pela Universidade de Vrije, na Holanda, descobriu que todos os dias são fabricados aproximadamente 2 milhões de novos pneus no mundo. Isto significa uma produção anual de 730 milhões. Ao mesmo tempo, hoje são transformados em sucata 800 milhões de unidades por ano. No Brasil, em 1993, cerca de $0,5 \%$ do lixo urbano brasileiro eram de pneus desgastados e fora de uso. Hoje são descartados no país aproximadamente 17 milhões de pneus por ano.

Assim, devido ao processo de recauchutagem, as bandas de rodagem dos pneus vêm a se tornarem resíduos. Desta maneira, conclui-se que a recauchutagem de pneus, que no Brasil segundo estimativas atinge $70 \%$ da frota de transporte de carga de passageiros, é uma fonte que contribui sensivelmente para o acúmulo desse tipo de material.

Neste trabalho avaliou-se a fabricação de blocos de concreto com a adição de resíduos de borracha, realizando-se uma análise nos mesmos através de dois tipos de ensaios: resistência à compressão simples e capacidade de absorção de água, com o intuito de se utilizar futuramente esse material alternativo na indústria da construção civil, visando a preservação ambiental.

\section{METODOLOGIA EMPREGADA}

Primeiramente foram realizadas a análise granulométrica e a determinação das massas específicas dos materiais (areia, pedrisco e resíduos de borracha).

Logo depois foi dado um tratamento especial aos resíduos de borracha, passando o material por um processo de seleção e classificação por peneiramento. Com a separação dos resíduos de borracha, a fração escolhida para a fabricação dos blocos foram os resíduos que passaram na peneira número 20 (abertura $0,8 \mathrm{~mm}$ ) da $\mathrm{ABNT}$ - Associação Brasileira de Normas Técnicas, que representam aproximadamente $37 \%$ do volume total do material.

O processo de classificação dos resíduos resultou numa fração de material mais uniforme, com grãos no tamanho máximo de cerca de $3 \mathrm{~mm}$. A figura 1 visualiza os resíduos de borracha em seu estado natural, já a figura 2 apresenta os resíduos na granulometria em que se encontram depois de peneirados. 


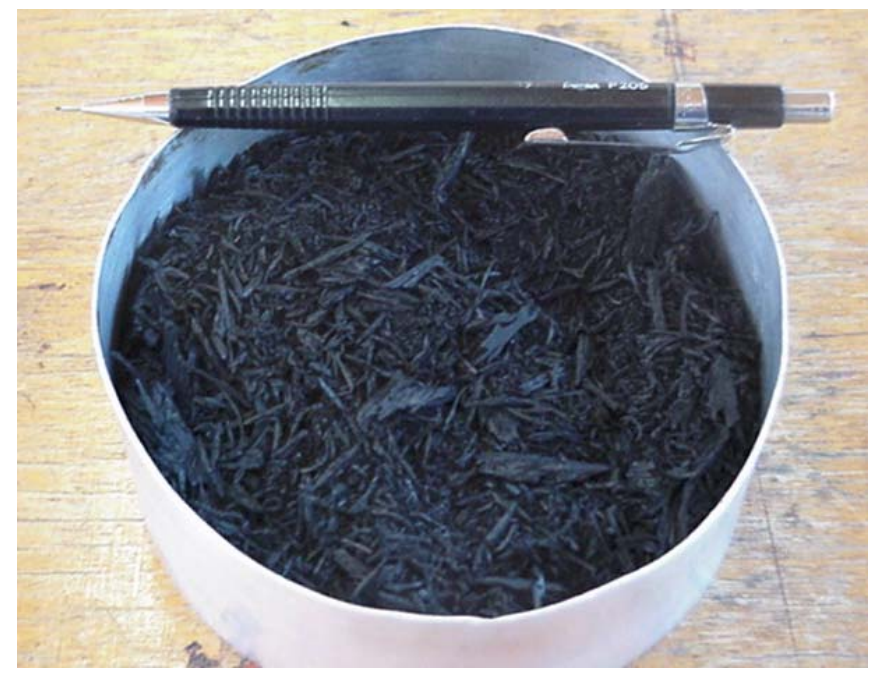

Figura 1 - Resíduos de borracha em seu estado natural.

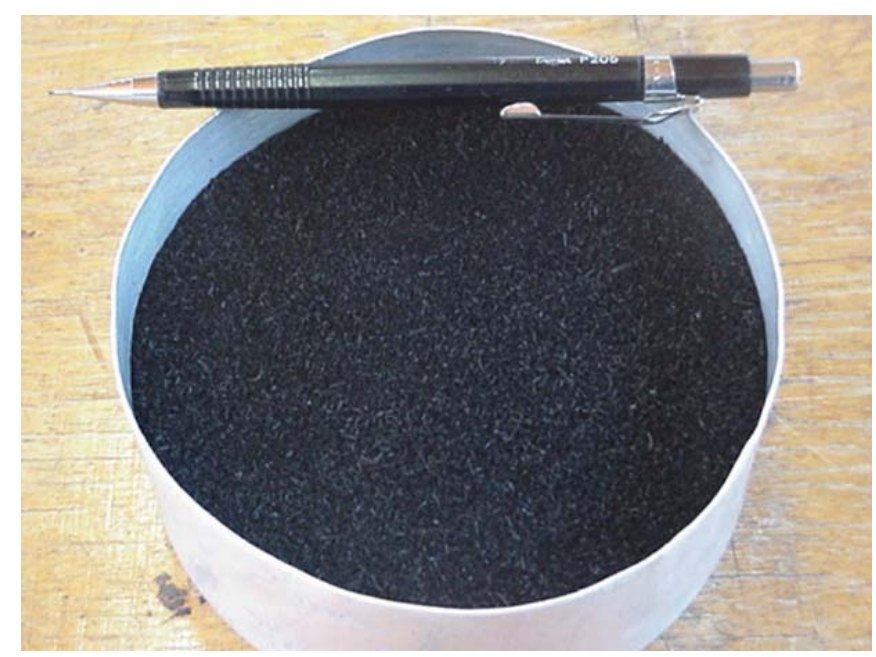

Figura 2 - Resíduos de borracha depois de passados na peneira número 20.

Foram confeccionados blocos de concreto designados pela sigla $\mathrm{M}-$ 15 , nas seguintes dimensões: $14 \mathrm{~cm}$ de largura x $39 \mathrm{~cm}$ de comprimento $\mathrm{x}$ $19 \mathrm{~cm}$ de altura, de acordo com a NBR - 6136/1994 (Bloco vazado de concreto simples para alvenaria estrutural) da ABNT. A fabricação dos blocos de concreto foi realizada em uma máquina vibro-prensa semiautomática (figura 3) indicada para produção em escala industrial compacta, dotada de silo para concreto, gaveta para enchimento da forma e alimentador de paletes com comando hidráulico centralizado. Os blocos foram moldados na Fábrica de pré-moldados "Concretic de Nipoã Artefatos de Cimento Ltda.", onde cinco diferentes dosagens de concreto 
com adição de resíduos de borracha foram executadas e uma feita sem adição de resíduos.

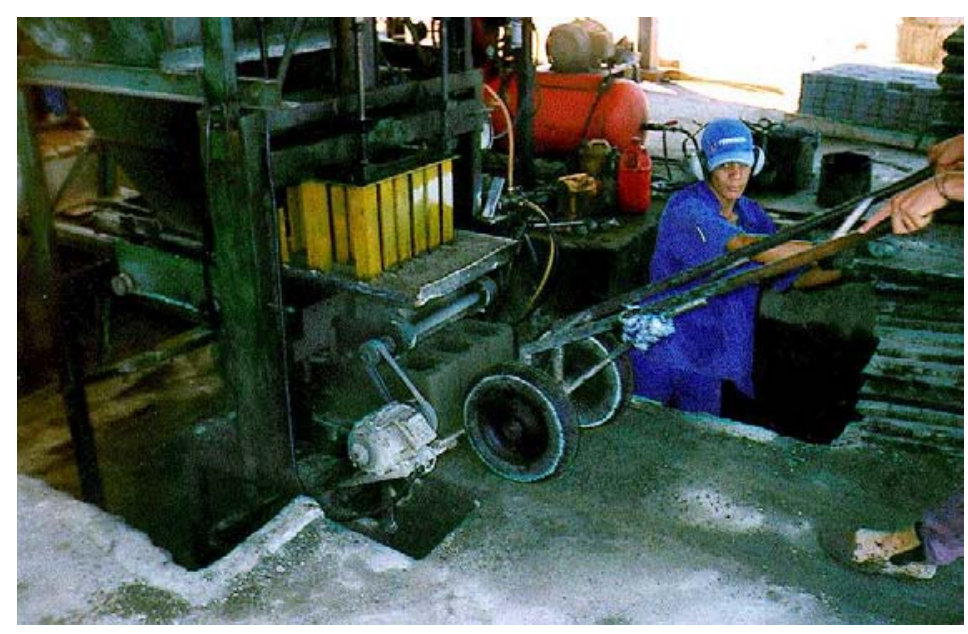

Figura 3 - Moldagem dos blocos na vibro-prensa semi-automática.

O preparo das quantidades de concreto foi realizado através de um método de dosagem empírico, onde foram determinadas as quantidades de cimento (CPV-ARI), agregados (areia e pedrisco), resíduos de borracha, aditivo (Rheomix 610-Lubricrete) e água para que o concreto satisfizesse, sobretudo, as condições de resistência previamente estabelecidas em normas técnicas.

De posse dos valores necessários para a definição das dosagens e após a obtenção dos blocos "referência", fabricados utilizamos a mesma dosagem empregada pela fábrica. Esta dosagem teve como objetivo servir de parâmetro de comparação para os blocos produzidos com os resíduos de borracha.

Como o objetivo foi produzir blocos de concreto estrutural, os materiais de todas as dosagens foram proporcionados em massa pois, esse método conduziu à obtenção de propriedades mais uniformes para $\mathrm{o}$ concreto.

A mistura do concreto foi feita em misturador de eixo horizontal, já que são mais eficientes para a mistura de um concreto considerado seco, utilizado na produção de blocos. O tempo de mistura foi o suficiente para obtenção da perfeita homogeneidade do concreto.

Após a mistura, o concreto cai por gravidade para o interior da gaveta da máquina vibro-prensa. Esta parte do equipamento encarrega-se de abastecer as formas de aço com o material. A gaveta também possui, no seu interior, hastes metálicas ou grades, denominadas agitadores, para 
facilitar a introdução do concreto nos vazios das formas. Estando a gaveta posicionada sobre a forma dos blocos, inicia-se uma vibração para permitir o seu preenchimento. A eficiência da vibração determina qual a quantidade de material que cada bloco terá e, conseqüentemente, seu grau de compactação. Esta variável foi fundamental para a obtenção de blocos resistentes.

Quando a forma encontra-se totalmente preenchida, a gaveta desloca-se para que as hastes metálicas comprimam a mistura no interior da mesma até o ponto em que os blocos atinjam a altura desejada. O intervalo de tempo em que as hastes permanecem sobre a mistura recebe o nome de tempo final. Durante o tempo final também ocorre a vibração da forma. Neste trabalho o tempo final foi variável em função das dosagens, ficando em torno de 5 a 10 segundos, sendo esta variável provocada principalmente pelas quantidades de resíduos de borracha nas composições do concreto. Depois de finalizada a prensagem do material de constituição dos blocos, ainda depositado no interior das formas, as hastes permanecem na mesma posição para que a forma se erga e ocasione a desforma, ficando os blocos sobre o palete. Por último, os paletes contendo os blocos recém-moldados são transportados até o local destinado à cura dos blocos.

A cura consistiu de aspersão de água, durante 7 dias. Aos 28 dias de idade foram ensaiados 36 blocos, sendo 6 para cada dosagem de concreto. $\mathrm{O}$ processo de ensaio para determinação da resistência à compressão simples seguiu o método descrito na norma NBR - 7184/1992 (Blocos vazados de concreto simples para alvenaria - Determinação da resistência à compressão) da ABNT. A figura 4 ilustra o bloco na prensa universal para ensaios, onde pode ser observada a presença dos pratos de aço que são acoplados na prensa e usados como apoio para que a distribuição de tensão no bloco seja uniforme.



Figura 4 - Bloco na prensa universal para ensaios. 
Com relação ao ensaio para determinação da absorção de água, este seguiu as prescrições da norma NBR - 12118/1991 (Blocos vazados de concreto simples para alvenaria - Determinação da absorção de água, do teor de umidade e da área líquida) da ABNT. Para o ensaio em questão foram utilizados 18 blocos, sendo 3 para cada dosagem de concreto.

\section{RESULTADOS E DISCUSSÃO}

A figura 5 apresenta as curvas granulométricas dos materiais, e a tabela 1 fornece os resultados dos ensaios de granulometria e massa específica dos materiais.

As tabelas 2 e 3 se referem às dosagens de concreto dos blocos, e as tabelas 4 e 5 aos resultados de resistência à compressão e absorção de água. $\mathrm{Na}$ seqüência, são apresentadas as figuras 6 e 7, onde podem ser visualizados os resultados dos ensaios de resistência à compressão simples e capacidade de absorção de água.

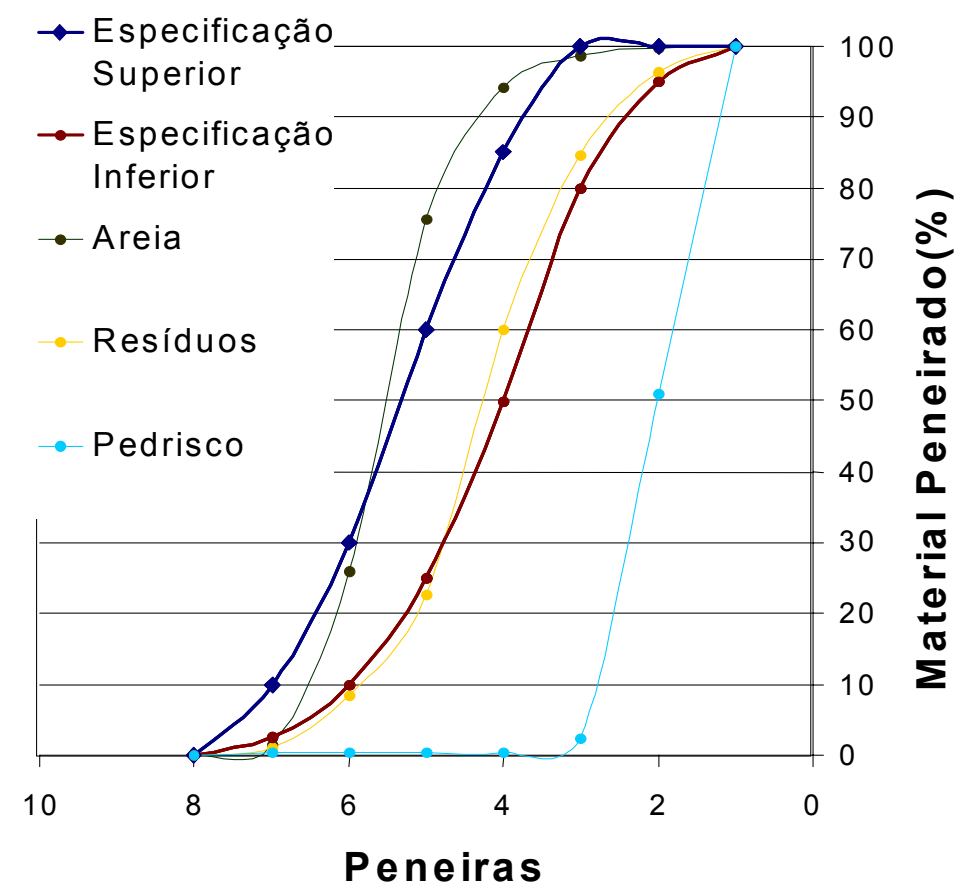

Figura 5 - Curvas granulométricas dos materiais. 
Tabela 1 - Ensaios de granulometria e massa específica dos materiais.

\begin{tabular}{|c|c|c|c|c|}
\hline Material & $\begin{array}{c}\text { Dimensão } \\
\text { Máxima } \\
(\mathbf{m m})\end{array}$ & $\begin{array}{c}\text { Módulo } \\
\mathbf{d e} \\
\text { Finura }\end{array}$ & $\begin{array}{c}\text { Massa } \\
\text { Específica } \\
\left(\mathbf{g} / \mathbf{c m}^{\mathbf{3}}\right)\end{array}$ & $\begin{array}{c}\text { Massa } \\
\text { Unitária } \\
\left(\mathbf{g} / \mathbf{c m}^{\mathbf{3}} \mathbf{)}\right.\end{array}$ \\
\hline Resíduos & $4,76^{*}$ & 2,07 & 1,09 & 0,27 \\
\hline Areia & 2,38 & 2,04 & 2,62 & 1,48 \\
\hline Pedrisco & 6,30 & 5,29 & 2,57 & 1,37 \\
\hline
\end{tabular}

*Resíduos no estado natural

Tabela 2 - Relação das dosagens dos materiais em volume (\%).

\begin{tabular}{|c|c|c|c|c|c|}
\hline \multicolumn{7}{|c|}{ Volume (\%) } \\
\hline Dosagens & Cimento & Areia & Pedrisco & Resíduos & Água \\
\hline Referência & 7,26 & 44,32 & 44,32 & & 4,10 \\
\hline Dosagem 1 & 12,21 & 42,76 & 28,13 & 10,00 & 6,90 \\
\hline Dosagem 2 & 11,15 & 41,58 & 27,97 & 13,00 & 6,30 \\
\hline Dosagem 3 & 11,99 & 40,83 & 27,39 & 13,00 & 6,78 \\
\hline Dosagem 4 & 10,89 & 43,35 & 24,61 & 15,00 & 6,15 \\
\hline Dosagem 5 & 11,69 & 39,95 & 26,75 & 15,00 & 6,61 \\
\hline
\end{tabular}

Tabela 3 - Relação das dosagens dos materiais em massa (\%).

\begin{tabular}{|c|c|c|c|c|c|}
\hline \multicolumn{6}{|c|}{ Massa (\%) } \\
\hline Dosagens & Cimento & Areia & Pedrisco & Resíduos & Água \\
\hline Referência & 5,92 & 47,32 & 43,80 & & 2,96 \\
\hline Dosagem 1 & 10,95 & 50,21 & 30,59 & 2,78 & 5,47 \\
\hline Dosagem 2 & 10,21 & 49,91 & 31,08 & 3,69 & 5,11 \\
\hline Dosagem 3 & 11,03 & 49,19 & 30,55 & 3,70 & 5,52 \\
\hline Dosagem 4 & 10,12 & 52,78 & 27,73 & 4,32 & 5,06 \\
\hline Dosagem 5 & 10,94 & 48,92 & 30,33 & 4,34 & 5,47 \\
\hline
\end{tabular}

Tabela 4 - Resultados obtidos nos ensaios de resistência à compressão simples.

\begin{tabular}{|c|c|c|c|}
\hline Dosagens & $\begin{array}{c}\text { Tensão (MPa) } \\
\text { Média }\end{array}$ & Variância & Desvio Padrão \\
\hline Referência & 4,89 & 0,1209 & 0,3477 \\
\hline Dosagem 1 & 7,11 & 1,0015 & 1,0007 \\
\hline Dosagem 2 & 4,54 & 0,0013 & 0,0358 \\
\hline Dosagem 3 & 4,98 & 0,0067 & 0,0817 \\
\hline Dosagem 4 & 3,89 & 0,0103 & 0,1013 \\
\hline Dosagem 5 & 4,60 & 0,0584 & 0,2416 \\
\hline
\end{tabular}






Figura 6 - Gráfico comparativo entre resistência à compressão x consumo de cimento.

Tabela 5 - Resultados obtidos nos ensaios de absorção de água.

\begin{tabular}{|c|c|c|c|}
\hline Dosagens & $\begin{array}{c}\text { Absorção (A\%) } \\
\text { Média }\end{array}$ & Variância & Desvio Padrão \\
\hline Referência & 5,33 & 0,0090 & 0,0950 \\
\hline Dosagem 1 & 3,66 & 0,0364 & 0,1909 \\
\hline Dosagem 2 & 6,27 & 0,0033 & 0,0577 \\
\hline Dosagem 3 & 6,05 & 0,0024 & 0,0493 \\
\hline Dosagem 4 & 8,27 & 0,2761 & 0,5255 \\
\hline Dosagem 5 & 7,05 & 0,6842 & 0,8272 \\
\hline
\end{tabular}

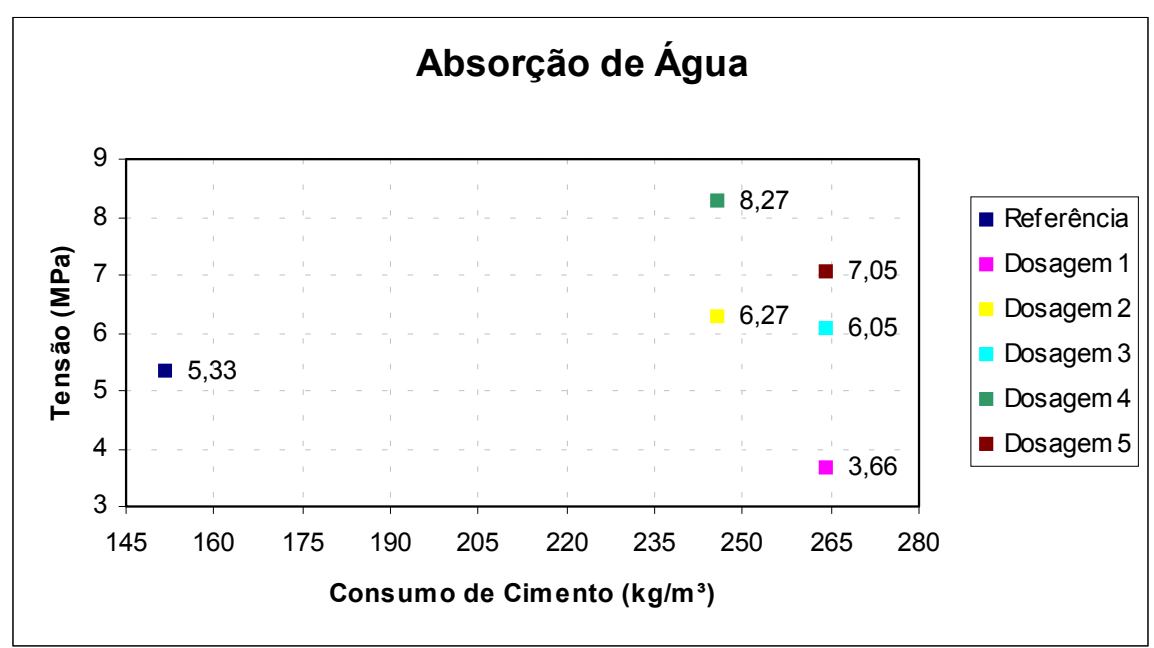

Figura 7 - Gráfico comparativo entre absorção de água x consumo de cimento.

Sabe-se que a introdução de qualquer tipo de resíduo no concreto implica em diminuição de resistência mecânica. Desta forma a dosagem de "referência" apresentou resultados de resistência à compressão e absorção de água dentro dos limites estabelecidos pelas normas da ABNT (NBR's 
7184/1992 e 12118/1991) ou seja, limite mínimo de 4,5 MPa no ensaio de resistência à compressão e limite máximo de $10 \%$ no ensaio de absorção de água.

Ficou constatado na figura 6, que a dosagem "1" contendo $10 \%$ (em volume) de resíduos, apresentou resultados de resistência à compressão na faixa de 7,0 Mpa, resultados estes considerados relativamente altos, mas as quantidades de resíduos e cimento utilizadas nas composições não eram ainda as desejadas. Entretanto, essa dosagem serviu de base para as outras que se sucederam no andamento do trabalho.Com relação à variação das quantidades de pedrisco e areia nas composições de concreto, podemos dizer que na fabricação dos blocos a menor variação destes materiais pode comprometer a dosagem. Por isso pode ser observado nas tabelas " 2 "e " 3 ", que dosagens semelhantes apresentaram resultados um pouco divergentes. Este fato foi ocasionado possivelmente pela homogeneização dos materiais envolvidos não ser a ideal, ou seja, o cimento + agregados + resíduos não obteve as quantidades necessárias para que o compósito final apresentasse o menor número de vazios possíveis, deixando assim de proporcionar a chamada compactação ótima do concreto dos blocos.

$\mathrm{O}$ consumo de cimento dos blocos estruturais foi fixado no limite máximo de $300 \mathrm{~kg} / \mathrm{m}^{3}$, de acordo com pesquisa realizada em diversas fábricas do estado de São Paulo, que torna esse limite variável em função do tipo de equipamento que é utilizado pelas fábricas de blocos, além da qualidade dos materiais constituintes dos mesmos. Em princípio, a preocupação era atingir a resistência mínima e não um menor consumo de cimento para a fabricação dos blocos. A principal finalidade do trabalho, era com a questão ambiental, ou seja, dar uma contribuição para a deposição final deste material poluidor e causador de doenças nocivas, sem ultrapassar o limite máximo de consumo de cimento estipulado pelas fábricas, com o intuito de amenizar o problema gerado pelos resíduos de pneus e não estimular o aumento do consumo de cimento pelo fato do alto índice de $\mathrm{CO}_{2}$ que é gerado durante a produção desse composto.

As dosagens "4" e "5" com 15\% (volume) de resíduos, apresentaram os resultados de absorção de água mais elevados, segundo a figura 7, possivelmente pelo fato das quantidades de areia serem as mais baixas e conterem a maior quantidade de resíduos em suas composições, o que teria dificultado o processo de compactação e vibração dos blocos na vibroprensa semi-automática. $\mathrm{Na}$ seqüência realizou-se tratamento estatístico onde o ensaio de resistência à compressão apresentou pequenas diferenças de tensões nas dosagens, com exceção da dosagem "1". Para os resultados de absorção de água as dosagens " 4 e 5" apresentaram os maiores valores. As diferenças de variância e desvio padrão foram causadas devido a vibroprensa ser acionada manualmente, o que faz com que o tempo final de 
vibração e prensagem seja diferente para cada palete que é introduzido no equipamento durante o processo de fabricação.

\section{CONCLUSÕES}

Este trabalho procurou avaliar as possibilidades do aproveitamento de resíduos de borracha para a fabricação de blocos de concreto com função estrutural. O estudo foi baseado nos resíduos oriundos da recauchutagem de pneus com granulometria compatível às de agregado miúdo.

De acordo com a análise dos resultados de resistência à compressão e absorção de água, conclui-se que para o bloco estrutural a quantidade considerada suficiente de resíduos na composição do concreto, sem que o mesmo venha diminuir a resistência dos blocos e ao mesmo tempo consumir o limite máximo de cimento $\left(300 \mathrm{~kg} / \mathrm{m}^{3}\right)$, é de $13 \%$ (em volume) com aproximadamente $245 \mathrm{~kg} / \mathrm{m}^{3}$ de cimento, conforme a dosagem " 2 ".

De acordo com essa análise global, pode-se dizer que esse tipo de bloco demonstra capacidade técnica podendo vir a competir com o bloco de concreto tradicional. A continuação deste trabalho com outras proporções de resíduos de borracha na composição do concreto dos blocos, permitiria a possibilidade de ampliar a validade das dosagens propostas.

Vale ressaltar que os blocos não foram avaliados quanto ao comportamento ao fogo, que é um parâmetro importante a ser considerado na qualidade técnica, principalmente pela borracha ser um material constituído de derivados de petróleo, evidenciando um campo a ser mais explorado futuramente pelas indústrias de blocos de concreto.

\section{AGRADECIMENTOS}

À Holcim Brasil;

À Araçá Recuperadora de Pneus Ltda;

À Fábrica de Pré-moldados Concretic de Nipoã - Artefatos de Cimento Ltda.

\section{REFERÊNCIAS}

ASSOCIAÇÃO BRASILEIRA DE NORMAS TÉCNICAS. NBR 6136 Bloco vazado de concreto simples para alvenaria estrutural. Rio de Janeiro, 1994. 
ASSOCIAÇÃO BRASILEIRA DE NORMAS TÉCNICAS. NBR 7184 Blocos vazados de concreto simples para alvenaria - Determinação da resistência à compressão. Rio de Janeiro, 1992.

ASSOCIAÇÃO BRASILEIRA DE NORMAS TÉCNICAS. NBR 12118 -

Blocos vazados de concreto simples para alvenaria - Determinação da absorção de água, do teor de umidade e da área líquida. Rio de Janeiro, 1991.

HOLANDA, O. G. J. Blocos de concreto para alvenaria estrutural. $42^{\circ}$ Congresso Brasileiro do Concreto, 2000, Fortaleza, IBRACON, 2000.

CONSULTAS COMPLEMENTARES

IRAJ, Z., JOHN, L., RADNOR, R. H. Particulate rubber included concrete compositions. Cement and Concrete Composites. v 18, Issue: 6, 460p., 1996.

TOPÇU, I., B. The properties of rubberized concretes. Cement and Concrete Research. v.25, n. 2, 304-310p., 1995. 